\title{
Pulmonary Echinococcus in children: a descriptive study in a LMIC
}

\author{
Dr. Mfingwana Lunga
}

Dissertation presented for the degree of Master of Philosophy in Pediatric Pulmonology in the Faculty of Medicine and Health Sciences at Stellenbosch University

December 2021

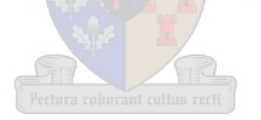

Supervisors: Prof Pierre Goussard

Dr Lizelle Van Wyk 


\section{Declaration}

By submitting this thesis electronically, I declare that the entirety of the work contained therein is my own, original work, that I am the sole author thereof (save to the extent explicitly otherwise stated), that reproduction and publication thereof by Stellenbosch University will not infringe any third party rights and that I have not previously in its entirety or in part submitted it for obtaining any qualification.

Date: December 2021

Copyright () 2021 Stellenbosch University All rights reserved 


\begin{abstract}
Background: Echinococcus granulosus is a major public health problem in lower middleincome countries (LMIC). Children are commonly diagnosed with cysts in the lungs and/or the liver.

Objectives: The purpose of this study was to describe a pediatric cohort diagnosed with pulmonary cystic echinococcus (CE) and treated with a combination of medical and surgical therapy.
\end{abstract}

Methods: This was a retrospective study performed between July 2017 and December 2020 at Tygerberg Hospital, South Africa. Clinical, laboratory, radiological, medical, and surgery-related outcomes were reviewed.

Results: The cohort consisted of 35 children, 17 (49\%) were male, with a mean age of $9 \pm 5.4$ years and a mean weight of $20.3 \pm 8.3 \mathrm{~kg}$. The most frequently encountered presenting symptom was cough (93\%) followed by fever $(70 \%)$. Isolated pulmonary CE accounted for the majority of cases (74\%) with left lower lobe predominance. A significant proportion of the cohort exhibited chest computed tomography (CT) characteristics consistent with complicated pulmonary CE. Eighteen (58\%) children had a positive indirect hemagglutination assay test result. All children received medical treatment whilst $30(86 \%)$ of children required surgery. Children with complicated pulmonary CE stayed a mean of $12.5 \pm 6.6$ days, while those with simple cysts stayed $6.8 \pm 1.5$ days.

Conclusion: Isolated pulmonary $\mathrm{CE}$ is common in children, whereas extrapulmonary cysts are uncommon. Pulmonary CE is diagnosed using CXR, and CT imaging. IHA serology has limited diagnostic utility for pulmonary CE. Combined surgery and chemotherapy remain the gold standard for treating pulmonary $\mathrm{CE}$.

Key words: Echinococcus granulosus; Pulmonary cystic echinococcus; Hydatid cyst; Thoracotomy; Albendazole 


\section{Acknowledgement}

I would like to express my gratitude to Professor Pierre Goussard and the pulmonology department for their support, guidance, and insight throughout this research project. My gratitude to the Department of Pediatrics and Child Health at Stellenbosch University and Tygerberg Hospital for the opportunity to train as a post-graduate student and senior registrar in pediatric pulmonology. 


\section{Table of Contents}

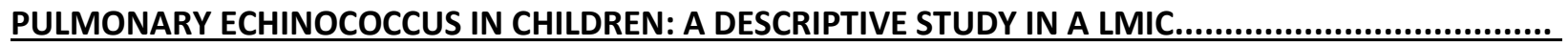

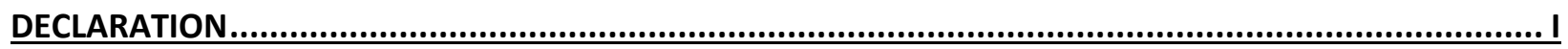

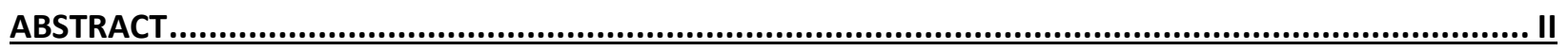

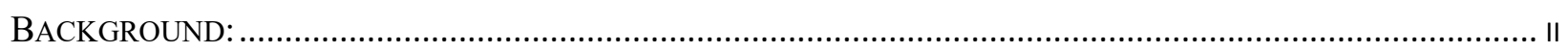

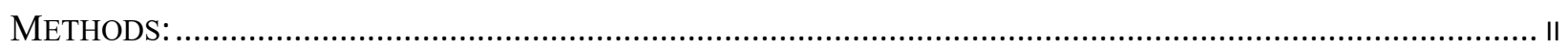

RESULTS:

CONCLUSION:

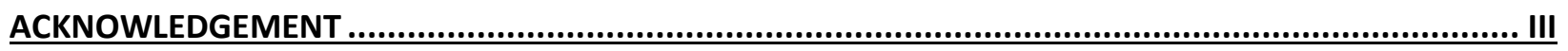

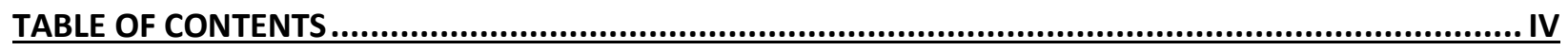

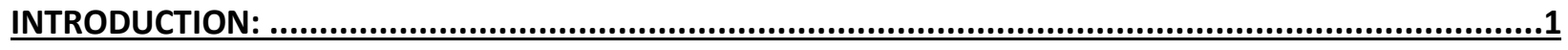

METHODS:

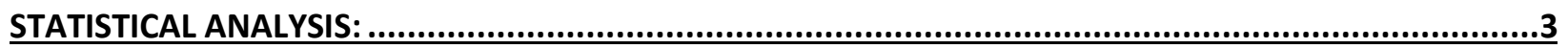

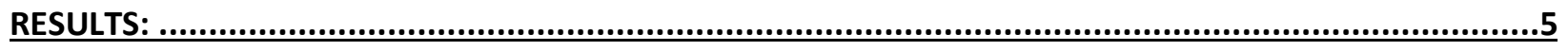

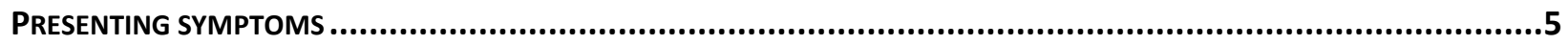

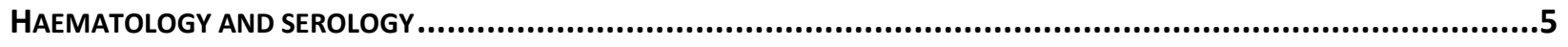

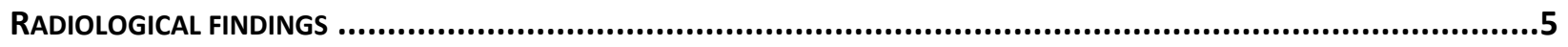

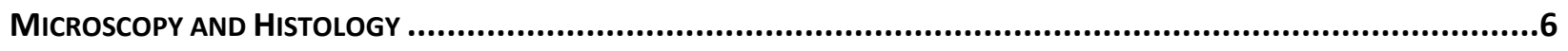

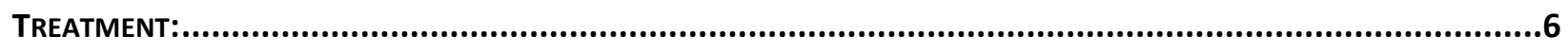

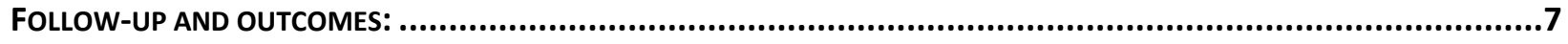

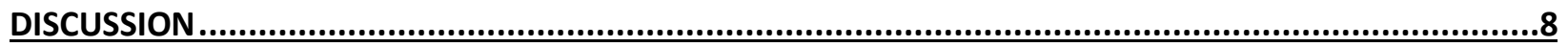

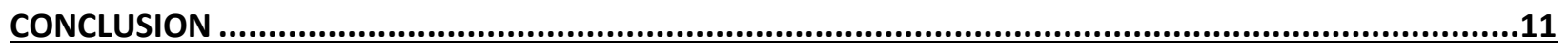

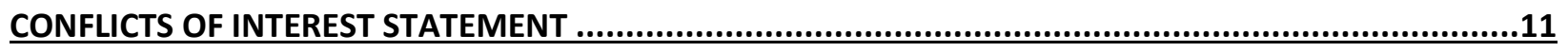

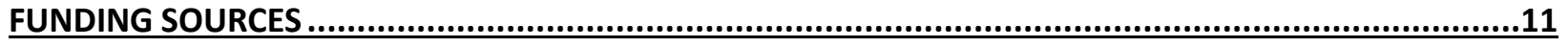

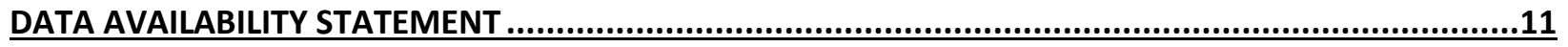

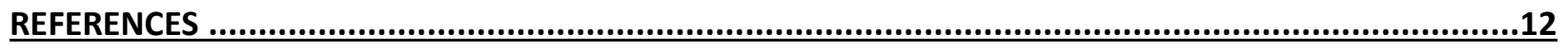

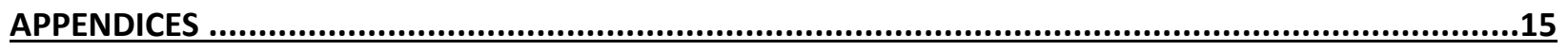

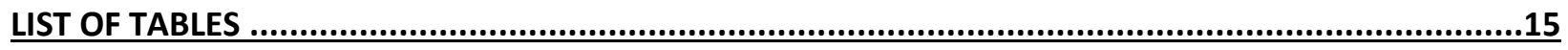

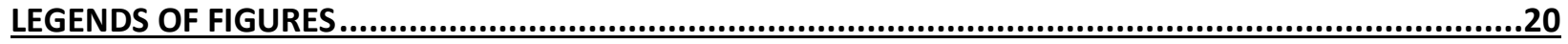




\section{Introduction:}

Echinococcosis is a worldwide public health problem causing considerable pediatric morbidity and mortality in endemic areas ${ }^{[1]}$. There is clear evidence that echinococcus is endemic to subSaharan Africa, however few studies outside of North Africa and the middle East have examined pediatric Cystic Echinococcal (CE) disease $\mathrm{e}^{[2,3]}$. Despite a well-known lifecycle, the presentation, accuracy of diagnostic methods and treatment outcomes of pediatric echinococcal disease in subSaharan and Southern Africa remains unclear. ${ }^{[2,3]}$

The presentation of CE varies by age. Unlike adults, where hepatic involvement is common, pulmonary $\mathrm{CE}$ is the dominant site in the pediatric population ${ }^{[4]}$. Pulmonary cyst/s are typically first seen on chest $\mathrm{x}$-ray (CXR), either as an incidental finding or following respiratory symptoms after cyst rupture or secondary infection of the cyst ${ }^{[5]}$. Pulmonary cysts have a broad differential diagnosis in children and a definitive diagnosis relies on the combination of imaging, serology, and histology. In countries with high infectious burdens from diseases such as Human Immune Deficiency Virus (HIV) and tuberculosis (TB) ${ }^{[2,3]}$, the diagnosis is additionally challenging, as atypical infections are more common than in developed countries. Furthermore, the sensitivity of serology for $\mathrm{CE}$ is not well described and despite improved imaging modalities such as computer tomography (CT), the definitive diagnosis prior to surgery remains challenging. There are currently no available standard, highly sensitive, and specific test for detecting antibodies in $\mathrm{CE}^{[6]}$.

The incidence of complications in pediatric pulmonary CE, including mass effect, cyst rupture, chemical pneumonitis, anaphylaxis, and death, remains unclear ${ }^{[7]}$. Whilst a few published adult studies have evaluated cyst size, cyst rupture, and surgical management as prognostic factors for postoperative complications, there is a paucity of data on prognostic factors in the pediatric population. There is also limited data to guide treatment type, duration of medical therapy and the optimal timing of surgery in the pediatric population ${ }^{[8-11]}$. 
In this article we describe the presenting symptoms, radiological findings, treatment outcomes and complications of a pediatric cohort with pulmonary $\mathrm{CE}$ and treated with a combination of medical and surgical therapy in South Africa.

\section{Methods:}

This retrospective, observational study was performed at Tygerberg Hospital (TCH).

Site: TCH is a tertiary public healthcare facility serving a population of over 2 million people in the eastern metropolis and surrounding rural districts of the Western Cape, South Africa.

Study population: The cohort included children aged 3-13-years, diagnosed with presumed pulmonary CE, admitted to the pediatric pulmonology unit at TCH between July 2017 and December 2020.

Data were collected from the paediatric pulmonology and radiology databases, paediatric intensive care unit (PICU) admission records, cardiothoracic surgery register, and pathology records.

Variables collected included sex, height, and age. Diagnostic data collected included results of CXR, CT, HIV status, complete blood counts, serum inflammatory markers, echinococcus serology, and histology.

The children were classified according to their anthropometric measurements into normal growth or moderate acute malnutrition (MAM). Children were classified as normal if Weight-forlength/height or BMI-for-age was $\geq-2 \mathrm{SD}$ and $\leq 2 \mathrm{SD}$ of the median, or mid-upper arm circumference $\geq 125 \mathrm{~mm}$ or as moderately malnourished if Weight-for-length/height or BMI-forage $\leq-2 \mathrm{SD}$ and $\geq-3 \mathrm{SD}$ of the median ${ }^{[12]}$, or mid-upper arm circumference $\geq 115 \mathrm{~mm}$ and $<125$ $\mathrm{mm}^{[13]}$. 
For this study, CE diagnosis was based on the features as per the CT chest. Pulmonary cysts were classified as complicated and uncomplicated. Complicated pulmonary CE was defined as a cyst that was a completely or a contained rupture. Features of a contained ruptured cyst are air crescent, and/or inverse crescent and/or air bubble signs [Figure(s) 1-2]. Features of complete rupture are any of the following: cumbo, dry cyst, rising sun, waterlily, whirl, mass within the cavity signs. Uncomplicated pulmonary CE was defined as well-defined, homogeneous lesions with low density and smooth, variable-thickness wall, irrespective of number or lobar location $^{[14]}$.

Histology/cytology was classified as either confirmed or uncertain echinococcus cyst.

Standard treatment for all cases included the initiation of albendazole $(20 / \mathrm{mg} / \mathrm{kg}$ daily) therapy prior to surgical removal of the cyst by a cardiothoracic surgeon. Following surgery all patients were admitted to the PICU for monitoring and pain relief. Treatment with Albendazole was continued for a total of 3 months ${ }^{[15]}$.

Patients were followed up for a minimum of 3 months following surgery and were reviewed for cyst reoccurrence by CXR (pulmonary CE), liver ultrasonography (hepatic, splenic CE) and echocardiogram (cardiac CE), dependent on initial CE presentation.

\section{Statistical analysis:}

Descriptive data were reported as mean and standard deviation, if normally distributed, and as median with interquartile ranges, if not normally distributed. Chi-square and Students t-test were performed, as appropriate, to compare groups. A p-value of $<0.05$ was considered statistically significant. 
Ethical permission for the study was obtained from the Stellenbosch University Committee for Human Research (HREC) Study number S19/09/193. A waiver of informed consent was applied for due to the retrospective nature of the study. 


\section{$\underline{\text { Results: }}$}

The cohort consisted of 35 children. One patient had tuberculosis as an additional infection, detected by nucleic acid amplification (GeneXpert MTB/RIF). No differences existed in children's demographics between complicated and uncomplicated cysts (Table 1).

Table 1: Clinical characteristics of children with pulmonary echinococcal cyst $(\mathrm{n}=35)$

Presenting symptoms: Cough $\mathrm{n}=32(91 \%)$ was the most common presenting symptom, followed by fever $n=22(63 \%)$, chest pain $n=13(37 \%)$, and shortness of breath $n=9(26 \%)$. There were no cases of haemoptysis or cyst fluid expectoration. No differences existed in children's presenting symptoms between complicated and uncomplicated cysts (online supporting material Table 2).

Haematology and serology. Eosinophilia was detected in only a few patients. The majority of children tested positive for antibodies. No differences existed between groups of children, except for CRP and positive serology (Table 1).

Radiological findings: CXR was performed as the initial radiological investigation, after which all patients underwent chest $\mathrm{CT}$ and abdominal sonography (Table 2, online supporting material Table 1).

Table 2: CT features of pulmonary echinococcal cysts in children at the time of presentation

The majority of the cohort had a single lobe involvement on chest CT scan, and the majority of lesions were localised to a single lung (Table 2). The left lower lobe of the lung was most frequently affected $n=16$ (46\%), followed by the left upper lobe $n=10(29 \%)$, right lower lobe $n=9(26 \%)$, right upper lobe $n=6(17 \%)$, right middle lobe $n=5(14 \%)$, and lingula $n=2(6 \%)$.

Similar findings were apparent on CXR (online supporting material Table 1). CT chest, however, was more accurate than CXR in identifying ruptured pulmonary CE cysts ( 27 vs $15, p=0.005$, respectively) 
Complicated pulmonary CE was present in $n=27$ (77\%) of cases (Table 2). Extra-pulmonary involvement was identified in $8(23 \%)$ cases (Table 2$)$.

Microscopy and Histology: Only 30 children underwent surgery in our unit; the remaining 5 children were either lost to follow-up or refused surgery. Histology of excised cysts or aspirated cyst content provided a definitive diagnosis in $22(73 \%)$ of the cases, whilst $3(10 \%)$ were uncertain and $5(17 \%)$ specimens were not suitable for histological evaluation. In $8(26 \%)$ of histologically confirmed CE cases, serology was negative.

In uncomplicated cases the specimens consisted of the outer laminated, acellular, chitinous layer with either viable or non-viable germinal layer and brood capsules (Figure 1). In some cases, there might be a layer of acute inflammatory cells present on the outside of the capsule. In complicated cases, portions of the surrounding lobe were also resected and showed various stages of organizing inflammatory process (Figure 2).

Treatment: All patients received medical treatment with oral albendazole $20 \mathrm{mg}$ /day. Medication was initiated at least one week prior to surgery. Twenty-nine children underwent a single-stage cystectomy via a posterolateral thoracotomy and one child a median sternotomy, as deemed appropriate by the cardiothoracic surgeon. Patients with multiple extra-pulmonary organ involvement underwent a staged surgical procedure.

Operative complications included air leak syndromes [pneumothorax $n=2$ (7\%), surgical emphysema $n=1(3 \%)]$, haemothorax necessitating blood transfusion $n=3(10 \%)$, post-operative sepsis $n=3(10 \%)$, and anaphylaxis $n=3(10 \%)$. One patient required a repeat thoracotomy for a massive haemothorax. 
Follow-up and outcomes: The average length of stay was $9.0 \pm 5.4$ days. Children with complicated CE stayed an average of $12.5 \pm 6.6$ days, while those with simple cysts stayed an average of $6.8 \pm 1.5$ days $(\mathrm{p}<0.001)$. Over the three-month post-operative follow-up period, no complications or recurrences of cysts were observed. 


\section{$\underline{\text { Discussion }}$}

We present a cohort of children with pulmonary cystic echinococcal (CE) disease managed with medical and surgical intervention, with minimal complications and no reoccurrences at 3 months.

The diagnosis of pulmonary CE remains challenging and relies on appropriate imaging (CXR and CT chest ${ }^{[14-16]}$, as serology and histology can often not establish a definitive diagnosis ${ }^{[17]}$. Pulmonary $\mathrm{CE}$ has a significant risk of acute complications pre and post-surgical intervention $^{[10,18-20]}$.

This study indicates that the lung is the most common site of CE in children, similar to other pediatric data ${ }^{[4,5]}$. Pulmonary cysts grow slowly and are often asymptomatic until complications such as mass effect, rupture or secondary infection, occur ${ }^{[21]}$. Non-specific respiratory symptoms, including cough, fever, chest pain, and shortness of breath, were common in our patients, similar to previously published pediatric studies ${ }^{[10,15,22,23]}$.

In the current study, no children presented with haemoptysis or cyst fluid expectoration, despite the high incidence of cyst rupture.

The majority of primary infections present as a single cyst; however, multiple cysts and involvement of multiple organs have been reported ${ }^{[7,20,24]}$. This phenomenon was also observed in this cohort, where most children had a single pulmonary cyst. In the current study, the left lower lobe was most commonly affected, similar to previously published studies that indicated the lower lobes to be the most common site of pulmonary $\mathrm{CE}^{[14]}$. In contrast to published studies, only a few cases of giant hydatid cysts were present in this cohort ${ }^{[14,21]}$

The diagnosis of pulmonary $\mathrm{CE}$ is made using a combination of imaging techniques, serological testing and histology of the excised cyst wall and cyst fluid content ${ }^{[9,15,25]}$. The radiological findings of pulmonary $\mathrm{CE}$ depends on the presence of complications and associated pulmonary 
findings ${ }^{[14,15]}$. Cysts are classified into two broad categories: simple cysts (cysts with smooth walls) and complicated cysts (ruptured cysts or infected cysts) ${ }^{[14]}$.

Cumbo, Waterlily, and Whirl signs are all well-described radiological signs of ruptured cysts on CT Chest ${ }^{[14,15]}$. CXR are usually the initial radiological examination. However, compared to CT chest, CXR has limited sensitivity and, if available, CT chest is preferable ${ }^{[9,15,25]}$. While sonography is beneficial for identifying, staging, and monitoring hepatic cysts $^{[25]}$, its role in identifying pulmonary CE is unknown, and no studies, to date, have examined its use in pediatric pulmonary CE.

Serological tests for CE lack sensitivity and cannot differentiate between Echinococcal exposure and active disease $\mathrm{e}^{[17,25]}$. The current study's findings indicate that IHA in pediatric pulmonary $\mathrm{CE}$, demonstrated limited diagnostic utility. Newer tests, such as counter-immunelectrophoresis and enzyme-linked immunosorbant assay, have improved diagnostic sensitivity and should be used for both screening and diagnoses ${ }^{[17]}$.

Microscopic and histological examinations can aid in the diagnosis of $\mathrm{CE}^{[26]}$. Additionally, our data indicate that inflammatory markers are slightly elevated in complicated pulmonary CE compared to uncomplicated, an observation that will need to be confirmed in a larger data set. (Table 1)

While surgical intervention is the preferred method of treating pulmonary CE, in some patients, pharmacotherapy may be beneficial ${ }^{[15,21]}$. There is conflicting evidence to guide treatment of pediatric complicated pulmonary $\mathrm{CE}^{[27]}$ and no randomized trials comparing different treatment strategies have been conducted. The optimal timing of surgery is uncertain and requires additional investigation.

In this cohort, surgery for pulmonary CE was associated with some postoperative complications but a had a generally positive outcome, similar to the majority of studies ${ }^{[10,22,28]}$. The majority of children in this study had complicated ruptured cysts prior to surgery. Cyst rupture is associated with significant pulmonary inflammation, anaphylaxis and secondary infection that increases the 
risk of surgical complication ${ }^{[14,15]}$. Additionally, patients with complicated pulmonary CE have a longer duration of hospitalization following surgical intervention.

Children in this study recovered from pulmonary CE and were asymptomatic at the end of the follow up period.

Several limitations apply to the current study. This was a single center, retrospective study which is unable to assess for local risk factors. Five patients were lost to follow-up, and some patients did not have serology performed, which may have skewed results. It will be beneficial to confirm these findings with multicenter prospective studies with a larger sample size. 


\section{Conclusion}

Pulmonary CE causes considerable respiratory morbidity in children. Children rarely present prior to cyst rupture, complicating their care and potentially increasing the risk of further complications. The diagnosis of pulmonary $\mathrm{CE}$ relies on a combination of CXR, CT imaging and serology. However serological tests, such as IHA, have a limited diagnostic utility. While a combination of surgery and chemotherapy remains the gold standard for treating pulmonary CE, patients with complicated pulmonary CE require a longer hospital stay following surgical intervention.

\section{Conflicts of Interest Statement}

All authors have no conflict of interest to declare

\section{Funding Sources}

No funds, grants or other financial support was received.

\section{$\underline{\text { Data Availability Statement }}$}

All data generated or analyzed during this study are included in this article and its supplementary material files. Further enquiries may be directed to the corresponding author 


\section{$\underline{\text { References }}$}

[1] Wen H, Vuitton L, Tuxun T, Li J, Vuitton DA, Zhang W, et al. Echinococcosis: Advances in the 21st century. Clin Microbiol Rev 2019;32. https://doi.org/10.1128/CMR.00075-18.

[2] Wahlers K, Menezes CN, Wong ML, Zeyhle E, Ahmed ME, Ocaido M, et al. Cystic echinococcosis in sub-Saharan Africa. Lancet Infect Dis 2012;12:871-80. https://doi.org/10.1016/S1473-3099(12)70155-X.

[3] Wahlers K, Menezes CN, Wong M, Mogoye B, Frean J, Romig T, et al. Human cystic echinococcosis in South Africa. Acta Trop 2011;120:179-84. https://doi.org/10.1016/j.actatropica.2011.08.006.

[4] Keskin E, Okur H, Zorludemir U, Olcay I, Ertaskin I. Hydatid cysts in children. J Chir (Paris) 1991;128:42-4.

[5] Fahimzad A, Karimi A, Tabatabaei SR, Armin S, Ghanaei RM, Fallah F, et al. Overview of hydatid disease in Iranian children. Arch Pediatr Infect Dis 2015;3. https://doi.org/10.5812/pedinfect.30084v2.

[6] Mcmanus DP, Zhang W, Li J, Bartley PB. Echinococcosis 2003;362:1295-305.

[7] Ndlovu M, Thula SA, Mphahlele REM, Masekela R. Pulmonary hydatidosis: Still unrecognised in endemic regions - A 10-year review. SAJCH South African J Child Heal 2018;12:13-5. https://doi.org/10.7196/SAJCH.2018.v12i2.1433.

[8] Ufuk Cobanoglu and Selvi Asker. Complications of Hydatid Cysts in the Lung. J Surg Surg Res 2015;1:6. https://doi.org/10.17352/2454-2968.000006.

[9] Morar R, Feldman C. Pulmonary echinococcosis. Eur Respir J 2003;21:1069-77. https://doi.org/10.1183/09031936.03.00108403.

[10] Durakbasa CU, Sander S, Sehiralti V, Tireli GA, Tosyali AN, Mutus M. Pulmonary hydatid disease in children: Outcome of surgical treatment combined with perioperative albendazole therapy. Pediatr Surg Int 2006;22:173-8. https://doi.org/10.1007/s00383-005$1611-6$.

[11] Erdem CZ, Erdem LO. Radiological characteristics of pulmonary hydatid disease in children: Less common radiological appearances. Eur J Radiol 2003;45:123-8. https://doi.org/10.1016/S0720-048X(02)00054-2. 
[12] de Onis M, Onyango A, Borghi E, Siyam A, Blössner M, Lutter C, et al. Worldwide implementation of the WHO Child Growth Standards. Public Health Nutr 2012;15:160310. https://doi.org/10.1017/S136898001200105X.

[13] Dukhi N, Sartorius B, Taylor M. Mid-upper arm circumference (MUAC) performance versus weight for height in South African children (0-59 months) with acute malnutrition. South African J Clin Nutr 2017;30:49-54. https://doi.org/10.1080/16070658.2016.1255483.

[14] Durhan G, Tan AA, Düzgün SA, Akkaya S, Arıyürek OM. Radiological manifestations of thoracic hydatid cysts: pulmonary and extrapulmonary findings. Insights Imaging 2020;11. https://doi.org/10.1186/s13244-020-00916-0.

[15] Sarkar M, Pathania R, Jhobta A, Thakur BR, Chopra R. Cystic pulmonary hydatidosis. Lung India 2016;33:179-91. https://doi.org/10.4103/0970-2113.177449.

[16] Fatimi S, Butt NW, Saleem T, Beg MA. Hydatid cyst disease of the thorax. Rev Infect $2010 ; 1: 42$.

[17] Biava MF, Dao A, Fortier B. Laboratory diagnosis of cystic hydatic disease. World J Surg 2001;25:10-4. https://doi.org/10.1007/s002680020002.

[18] Burgos R, Varela A, Castedo E, Roda J, Montero CG, Serrano S, et al. Pulmonary hydatidosis: Surgical treatment and follow-up of 240 cases. Eur J Cardio-Thoracic Surg 1999;16:628-35. https://doi.org/10.1016/S1010-7940(99)00304-8.

[19] Parelkar S V., Gupta RK, Shah H, Sanghvi B, Gupta A, Jadhav V, et al. Experience with video-assisted thoracoscopic removal of pulmonary hydatid cysts in children. $\mathrm{J}$ Pediatr Surg 2009;44:836-41. https://doi.org/10.1016/j.jpedsurg.2008.11.029.

[20] Aytaç A, Yurdakul Y, Ikizler C, Olga R, Saylam A. Pulmonary Hydatid Disease: Report of 100 Patients. Ann Thorac Surg 1977;23:145-51. https://doi.org/10.1016/S00034975(10)64088-X.

[21] Arroud M, Afifi MA, Ghazi K El, Nejjari C, Bouabdallah Y. Lung hydatic cysts in children: Comparison study between giant and non-giant cysts. Pediatr Surg Int 2009;25:37-40. https://doi.org/10.1007/s00383-008-2256-z.

[22] Aldahmashi M, Alassal M, Kasb I, Elrakhawy H. Conservative Surgical Management for Pulmonary Hydatid Cyst: Analysis and Outcome of 148 Cases. Can Respir J 2016;2016. 
https://doi.org/10.1155/2016/8473070.

[23] Şişmanlar Eyüboğlu T, Ramaslı Gürsoy T, Tana Aslan A, Pekcan S, Budakoğlu Iİ. Tenyear follow-up of children with hydatid cysts. Turk Pediatr Ars 2019;54:173-8. https://doi.org/10.14744/TurkPediatriArs.2019.24119.

[24] Ben Abdallah AK, Zouari M, Haj Mansour M, Abid I, Ben Dhaou M, Jallouli M, et al. Hydatid cyst of the lung in children: A diagnosis not to be missed. Iran J Public Health 2019;48:767-9. https://doi.org/10.18502/ijph.v48i4.1012.

[25] Brunetti E, Kern P, Vuitton DA. Expert consensus for the diagnosis and treatment of cystic and alveolar echinococcosis in humans. Acta Trop 2010;114:1-16. https://doi.org/10.1016/j.actatropica.2009.11.001.

[26] Brunetti E, Kern P, Vuitton DA. Expert consensus for the diagnosis and treatment of cystic and alveolar echinococcosis in humans. Acta Trop 2010;114:1-16. https://doi.org/10.1016/j.actatropica.2009.11.001.

[27] Galanakis E, Besis S, Pappa C, Nicolopoulos P, Lapatsanis P. Treatment of complicated pulmonary echinococcosis with albendazole in childhood. Scand $\mathrm{J}$ Infect Dis 1997;29:638-40. https://doi.org/10.3109/00365549709035913.

[28] Topçu S, Kurul IC, Taştepe I, Bozkurt D, Gülhan E, Çetin G. Surgical treatment of pulmonary hydatid cysts in children. J Thorac Cardiovasc Surg 2000;120:1097-101. https://doi.org/10.1067/mtc.2000.110181. 


\section{$\underline{\text { Appendices }}$}

\section{$\underline{\text { List of tables }}$}

Table 2: Clinical characteristics of children with pulmonary echinococcal cyst $(\mathrm{n}=35)$

\begin{tabular}{|c|c|c|c|c|}
\hline \multirow{2}{*}{ Demographics } & \multirow{2}{*}{$\begin{array}{l}\text { Combined } \\
n=35\end{array}$} & \multirow{2}{*}{$\begin{array}{l}\text { Complicated } \\
\text { CE } n=27\end{array}$} & \multirow{2}{*}{$\begin{array}{l}\text { Uncomplicated } \\
\text { CE } n=8\end{array}$} & \multirow[t]{2}{*}{$p$-value } \\
\hline & & & & \\
\hline \multicolumn{5}{|c|}{ Demographics } \\
\hline Age, yrs., mean \pm SD & 7.02 .8 & $7.0 \pm 2.8$ & $7.0 \pm 2.9$ & 1.00 \\
\hline Males; n (\%) & $17(49)$ & $13(48)$ & $4(50)$ & 0.921 \\
\hline Weight, kg, mean \pm SD & $20.3 \pm 8.3$ & $20.0 \pm 8.7$ & $20.5 \pm 6.3$ & 0.881 \\
\hline Height, cm, mean \pm SD & $118 \pm 17.8$ & $113.0 \pm 18.4$ & $120.0 \pm 13.2$ & 0.325 \\
\hline HIV status tested negative, $\mathbf{n}(\%)$ & $30(86)$ & $23(85)$ & $7(88)$ & 0.833 \\
\hline Nutritional status; (normal) n (\%) & $26(74)$ & $20(74)$ & $6(75)$ & 0.955 \\
\hline $\begin{array}{l}\text { Nutritional status; (malnourished) n } \\
(\%)\end{array}$ & $6(17)$ & $8(30)$ & $1(13)$ & 0.343 \\
\hline \multicolumn{5}{|c|}{ Laboratory Investigations } \\
\hline White cell count $\left(\times 10^{9} / \mathrm{L}\right)$, mean $\pm \mathrm{SD}$ & $13.4 \pm 7.9$ & $16.9 \pm 8.3$ & $10.4 \pm 4.1$ & 0.041 \\
\hline Haemoglobin, g/dl, mean \pm SD & $11.1 \pm 1.58$ & $10.7 \pm 1.7$ & $11.5 \pm 0.6$ & 0.204 \\
\hline Eosinophils, $\left(\times 10^{9} / \mathrm{L}\right)$, mean $\pm \mathrm{SD}$ & $0.36 \pm 0.90$ & $0.4 \pm 1.0$ & $0.36 \pm 0.4$ & 0.913 \\
\hline Albumin, $g / L$, mean \pm SD & $34 \pm 6.3$ & $33.0 \pm 5.5$ & $37.0 \pm 2.8$ & 0.057 \\
\hline CRP, mg/L, Median (IQR) & $107(7-237)$ & $115(52-268)$ & $3(2.5-125)$ & 0.057 \\
\hline Positive serology; $\mathbf{n}(\%)^{a}$ & $18(58)$ & $16(59)$ & $2(25)$ & 0.095 \\
\hline
\end{tabular}

${ }^{\text {a }}$ Only 31 children received serology tests 
Table 2: CT features of pulmonary echinococcal cysts in children at the time of presentation

\begin{tabular}{|ll|}
\hline Classification & Patients $\boldsymbol{n}(\mathbf{\%})$ \\
\hline Uncomplicated & $8(22)$ \\
\hline Complicated & $27(77)$ \\
\hline Site & Patients $\boldsymbol{n}(\mathbf{\%})$ \\
\hline Single lobe, $\mathbf{n}(\%)$ & $26(74)$ \\
\hline Multiple lobe involvement, $\mathbf{n}(\%)$ & $9(26)$ \\
\hline Unilateral, $\mathbf{n}(\%)$ & $28(78)$ \\
\hline Bilateral, $\mathbf{n}(\%)$ & $7(20)$ \\
\hline Giant cyst $(>10 \mathrm{~cm}), \mathbf{n}(\%)$ & $6(17)$ \\
\hline Lung and other organ involved liver, $\mathbf{n}(\%)$ & $8(23)$ \\
\hline Lung \& liver only & $5 / 8(63)$ \\
\hline Lung, liver \& spleen & $1 / 8(13)$ \\
\hline Lung \& cardiac only & $1 / 8(13)$ \\
\hline Lung \& spleen only & $1 / 8(13)$ \\
\hline Features of complicated CE on CT & Patients $\boldsymbol{n}(\mathbf{\%})$ \\
\hline Parenchymal involvement (consolidation), $\mathbf{n}(\%)$ & $28(80)$ \\
\hline Ruptured cyst, $\mathbf{n}(\%)$ & $27(77)$ \\
\hline Pleural effusion, $\mathbf{n}(\%)$ & $9(26)$ \\
\hline Atelectasis, $\mathbf{n}(\%)$ & $6(17)$ \\
\hline & \\
\hline
\end{tabular}

c Ruptured cysts on CT-comprised of Cumbo sign, Waterlily sign, and Whirl sign 
Supplemental Table 1: Anatomical location of hydatid cysts (CXR versus CT)

\begin{tabular}{|l|r|r|}
\hline Lobe Involvement & Frequency $(n)$ CXR & Frequency $(n)$ CT \\
\hline Unilateral, $(n)$ & 5 & 28 \\
\hline Bilateral involvement, $(n)$ & 6 & 7 \\
\hline Right upper lobe, $(n)$ & 3 & 6 \\
\hline Right middle lobe, $(n)$ & 8 & 5 \\
\hline Right lower lobe, $(n)$ & 8 & 9 \\
\hline Left upper lobe, $(n)$ & 1 & 10 \\
\hline Lingula, $(n)$ & & \\
\hline Left lower lobe, $(n)$ & & \\
\hline
\end{tabular}


Supplemental Table 2: Clinical symptoms complicated versus non complicated

\begin{tabular}{|c|c|c|c|}
\hline Presenting symptoms & $\begin{array}{l}\text { Complicated } \\
n=27\end{array}$ & $\begin{array}{l}\text { Uncomplicated } \\
n=8\end{array}$ & P value \\
\hline Fever, n (\%) & $19(70)$ & $3(38)$ & 0.091 \\
\hline Cough, n (\%) & $25(93)$ & $7(88)$ & 0.652 \\
\hline Chest pain, n (\%) & $9(33)$ & $4(50)$ & 0.400 \\
\hline Shortness of breath, $n$ (\%) & $8(30)$ & $1(13)$ & 0.366 \\
\hline
\end{tabular}




\section{Legends of figures}

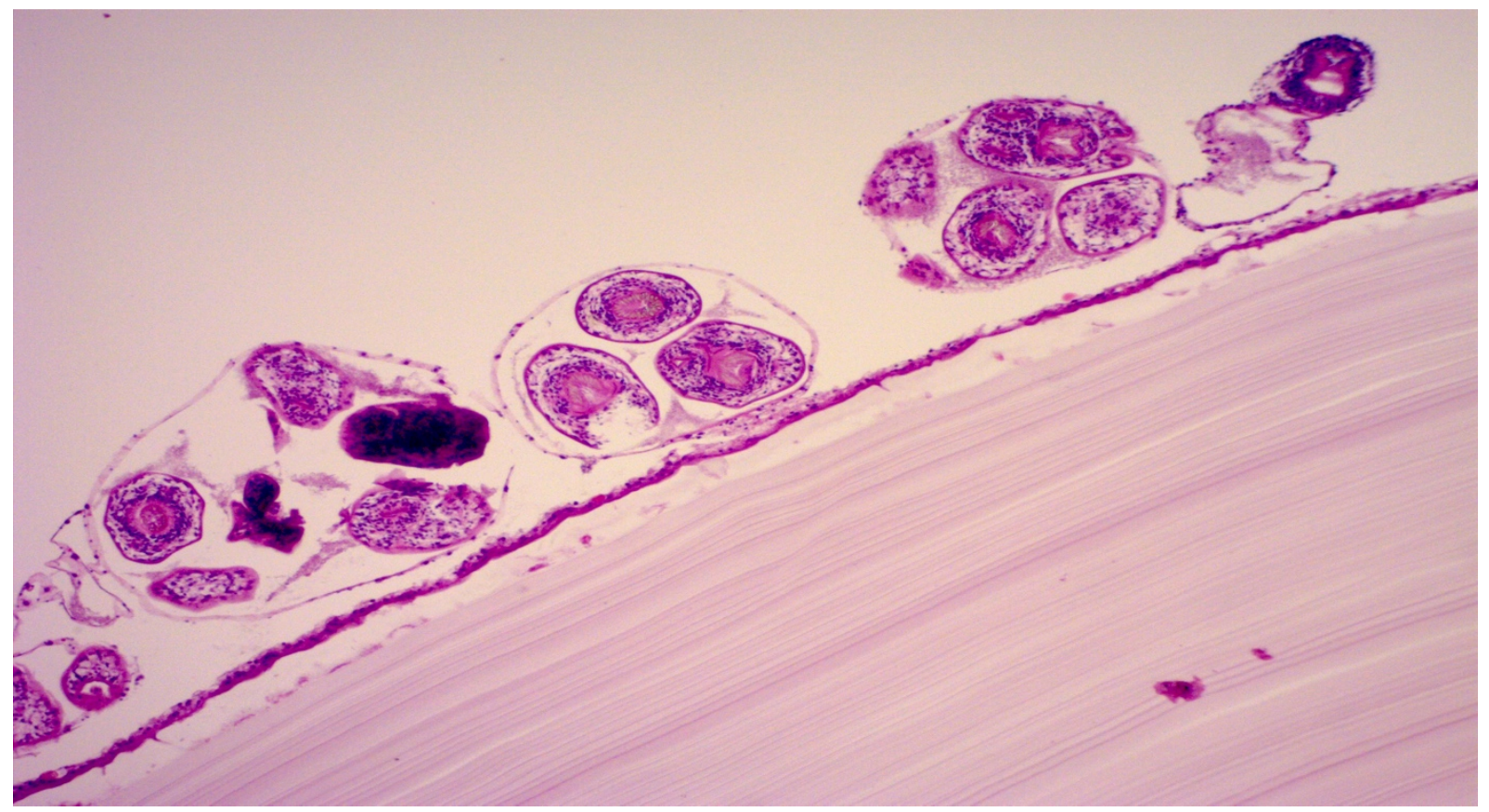

Figure 1: Shows a viable organism from an uncomplicated echinococcus resection with the middle, acellular, chitinous layer (bottom right), an inner germinal matrix layer and multiple brood capsules that contain scolexes with hooklits. Haematoxylin and eosin stain, 10x.

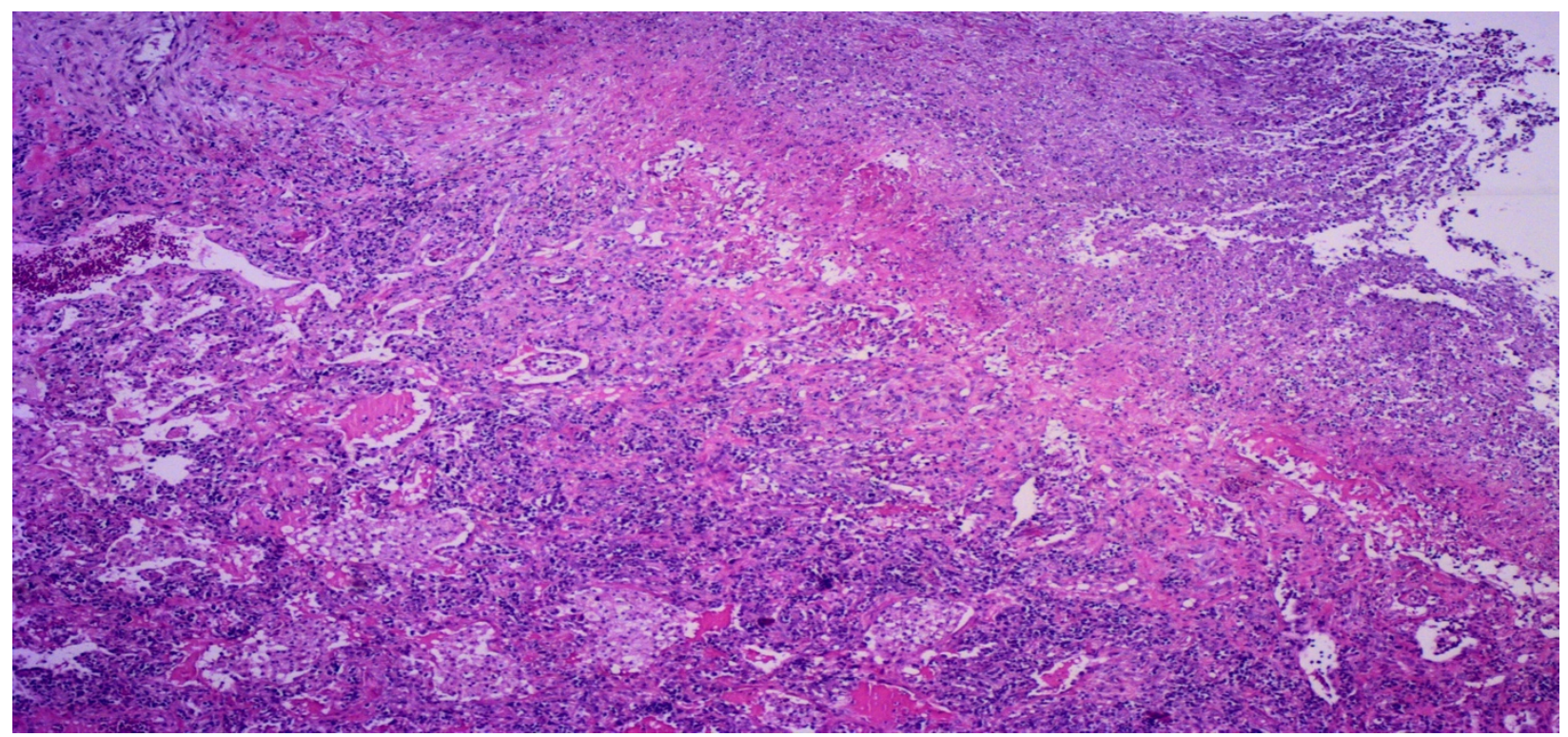

Figure 2: Lobectomy from a complicated echinococcosis case with a ruptured wall and necrotic fibrinopurulent material with fibrosis (indicative of outer layer) (upper right) with the lung parenchyma (bottom left) showing interstitial inflammation with fibrosis and foamy macrophages in the alveolar lumens. Haematoxylin and eosin stain, 4x. 

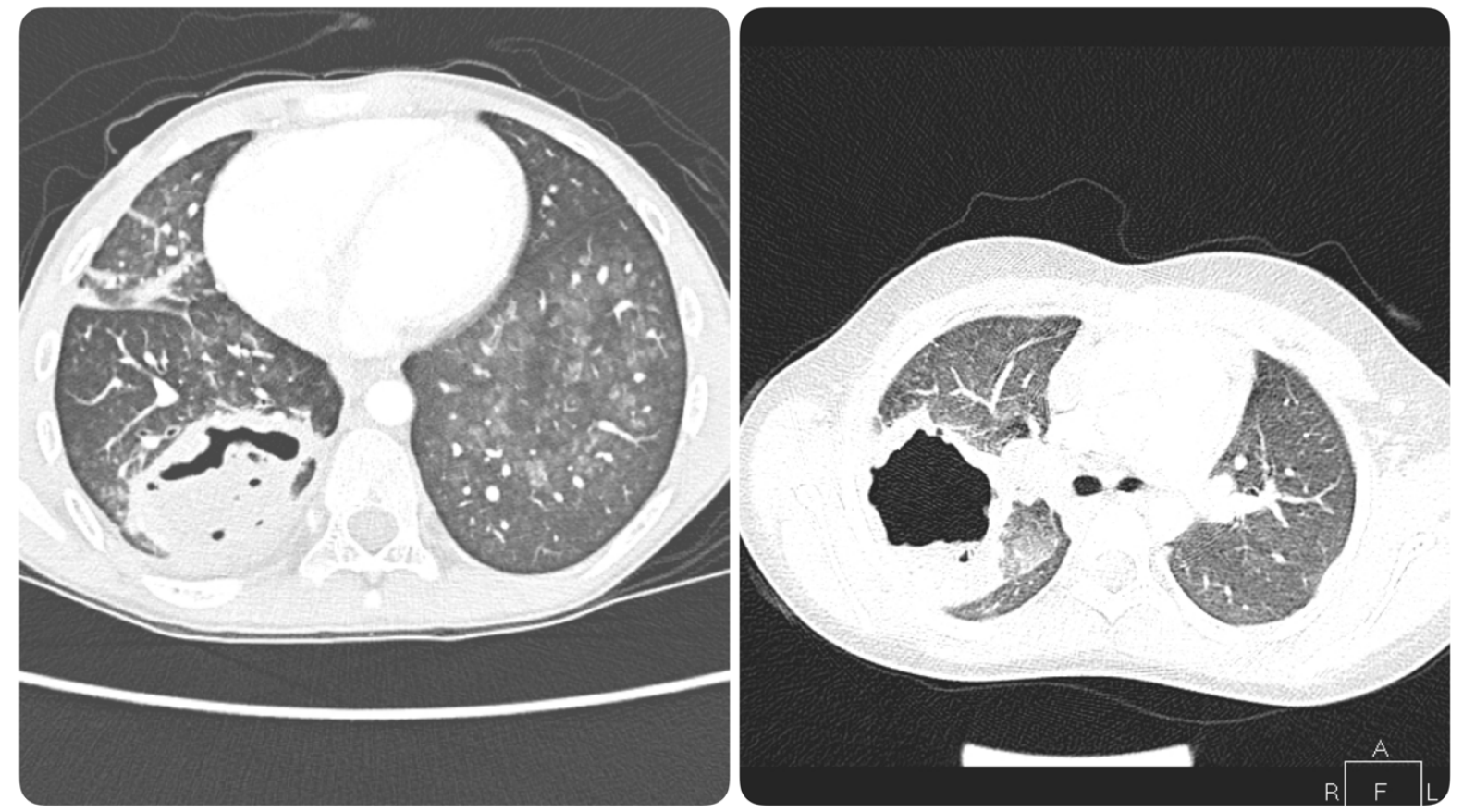

Figure 3: a-b Axial CT lung window images of various patients. (a) Imaging features of contained rupture. (b)The cyst, which resembled a water lily, was found peripherally and caused atelectasis in the pericystic lung tissue. 


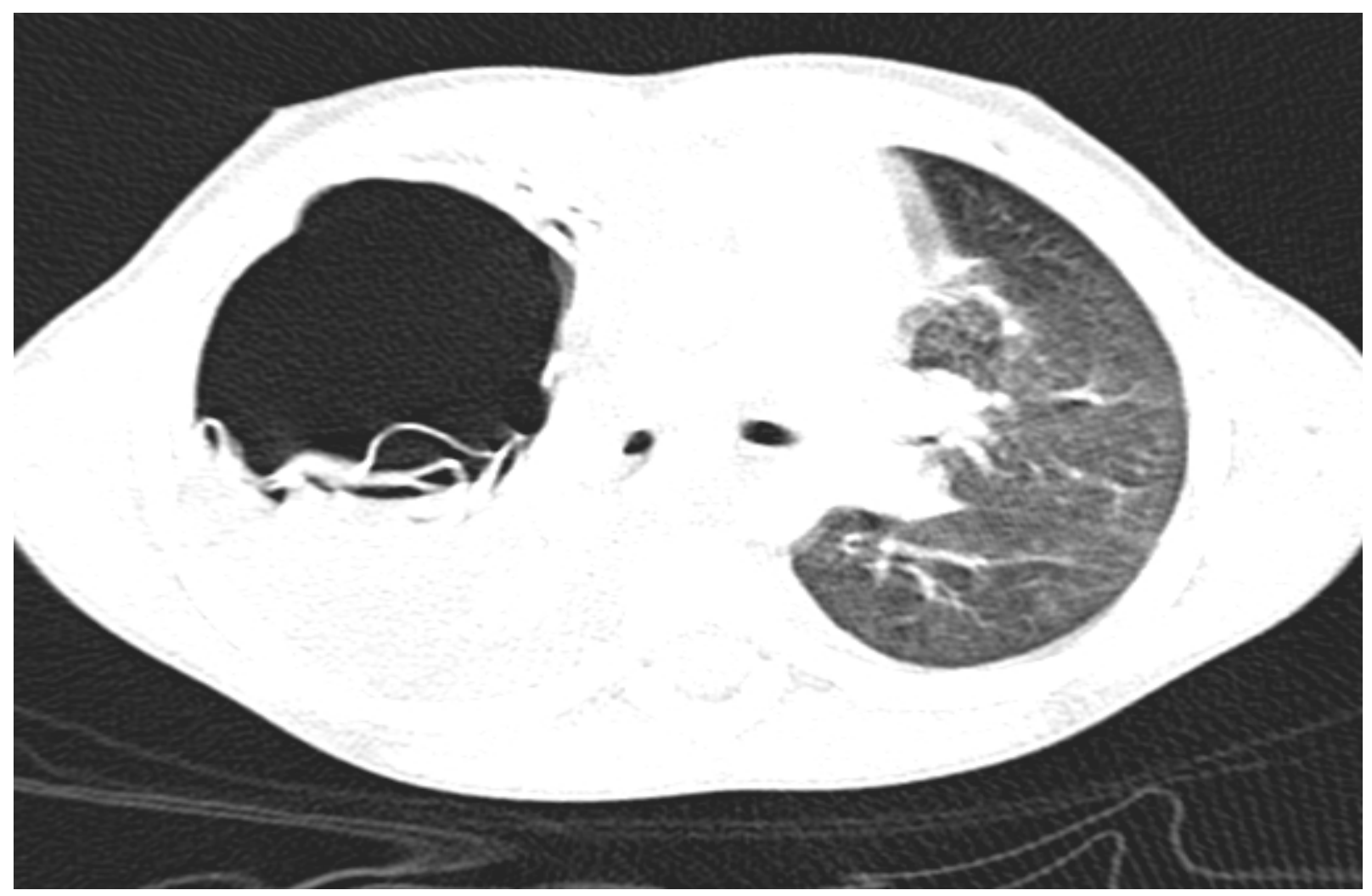

Figure 4: Axial CT showing a Complete cyst rupture 